\title{
Surgical approaches for resection of vestibular schwannomas: translabyrinthine, retrosigmoid, and middle fossa approaches
}

\author{
Roukoz Chamoun, M.D., ${ }^{1}$ Joel MacDonald, M.D., ${ }^{1}$ Clough Shelton, M.D., ${ }^{2}$ \\ and William T. Couldwell, M.D., Ph.D. ${ }^{1}$ \\ ${ }^{1}$ Department of Neurosurgery, Clinical Neurosciences Center; and ${ }^{2}$ Division of Otolaryngology, University of \\ Utah, Salt Lake City, Utah
}

\begin{abstract}
Surgical removal remains one of the key treatment modalities for vestibular schwannomas. A team approach between a neurotologist and a neurosurgeon offers the patient the expertise of both specialties and maximizes the chances for an optimal outcome. Vestibular schwannomas can typically be resected through 1 of 3 main surgical approaches: the translabyrinthine, the retrosigmoid, or the middle fossa approaches. In this report and videos, the authors describe and illustrate the indications and surgical techniques for the removal of these tumors. (http://thejns.org/doi/abs/10.3171/2012.6.FOCUS12190)
\end{abstract}

Key Words - vestibular schwannoma - surgical technique • translabyrinthine approach • retrosigmoid approach • middle fossa approach

$\mathrm{S}$ URGICAL removal remains one of the key treatment modalities for VSs. ${ }^{3} \mathrm{~A}$ team approach between a neurotologist and a neurosurgeon offers the patient the expertise of both specialties and maximizes safety and the chances for an optimal outcome. Vestibular schwannomas can typically be resected through 1 of 3 main surgical approaches: the translabyrinthine, ${ }^{2}$ the retrosigmoid,${ }^{4}$ or the middle fossa approaches. ${ }^{1}$ In this article, we describe and illustrate our indications and surgical technique for the removal of these tumors.

\section{The Translabyrinthine Approach}

The translabyrinthine approach (Fig. 1, Video 1) provides excellent access to the IAC.

VIDEo 1. Clip showing the translabyrinthine approach for resection of a VS. Click here to view with Media Player. Click here to view with Quicktime.

The translabyrinthine approach is chosen for patients with poor preoperative hearing and for patients with large tumors who have a low probability of hearing preservation. The size of the tumor is typically not a limiting factor for this approach. The approach has several advantages, including 1) it offers early identification of the facial nerve in the auditory canal, and 2) there is absolutely no need for cerebellar retraction.

The patient is positioned supine, and the head is rotated to the contralateral side. Somatosensory evoked potentials, motor evoked potentials, and facial nerve moni-

Abbreviations used in this paper: $\mathrm{CPA}=$ cerebellopontine angle; $\mathrm{IAC}=$ internal auditory canal; VS = vestibular schwannoma. toring are used. A hockey stick-shaped retroauricular skin incision extending behind the mastoid tip is made. The mastoidectomy is performed with the high-speed drill, and the sigmoid sinus, presigmoid dura mater, and middle fossa dura are exposed. The mastoid segment of the facial nerve is skeletonized. The eustachian tube is packed with bone wax and Surgicel to prevent CSF leakage.

Next, the labyrinthectomy is performed to access the IAC. The translabyrinthine approach exposes $270^{\circ}$ of the circumference of the IAC. The dura of the IAC is then opened. We prefer to open along the axis of the IAC and use a Y-shaped incision to open the dura in the posterior fossa. The facial nerve is located and confirmed using stimulation. The vestibular nerves are cut, and the tumor is dissected from the facial nerve. The presigmoid dura is then opened. The tumor is dissected from the cerebellum and the brainstem and is debulked using the ultrasonic aspirator.

It should be noted that the operative corridor is smaller with this approach and that debulking of the tumor is necessary prior to dissection of the tumor capsule from the brainstem and nerves. Once the tumor has been debulked, the extracapsular dissection proceeds more easily. The root entry zone of the facial nerve at the brainstem is identified and confirmed with stimulation. The flocculus and choroid plexus emerging from the lateral foramen are useful landmarks to identify the facial nerve origin just superior to the pontomedullary junction. The origin of the vestibulocochlear nerve at the brainstem is identified just ventral and superior to the facial nerve origin, where it is then divided. This allows the tumor to be gently reflected 

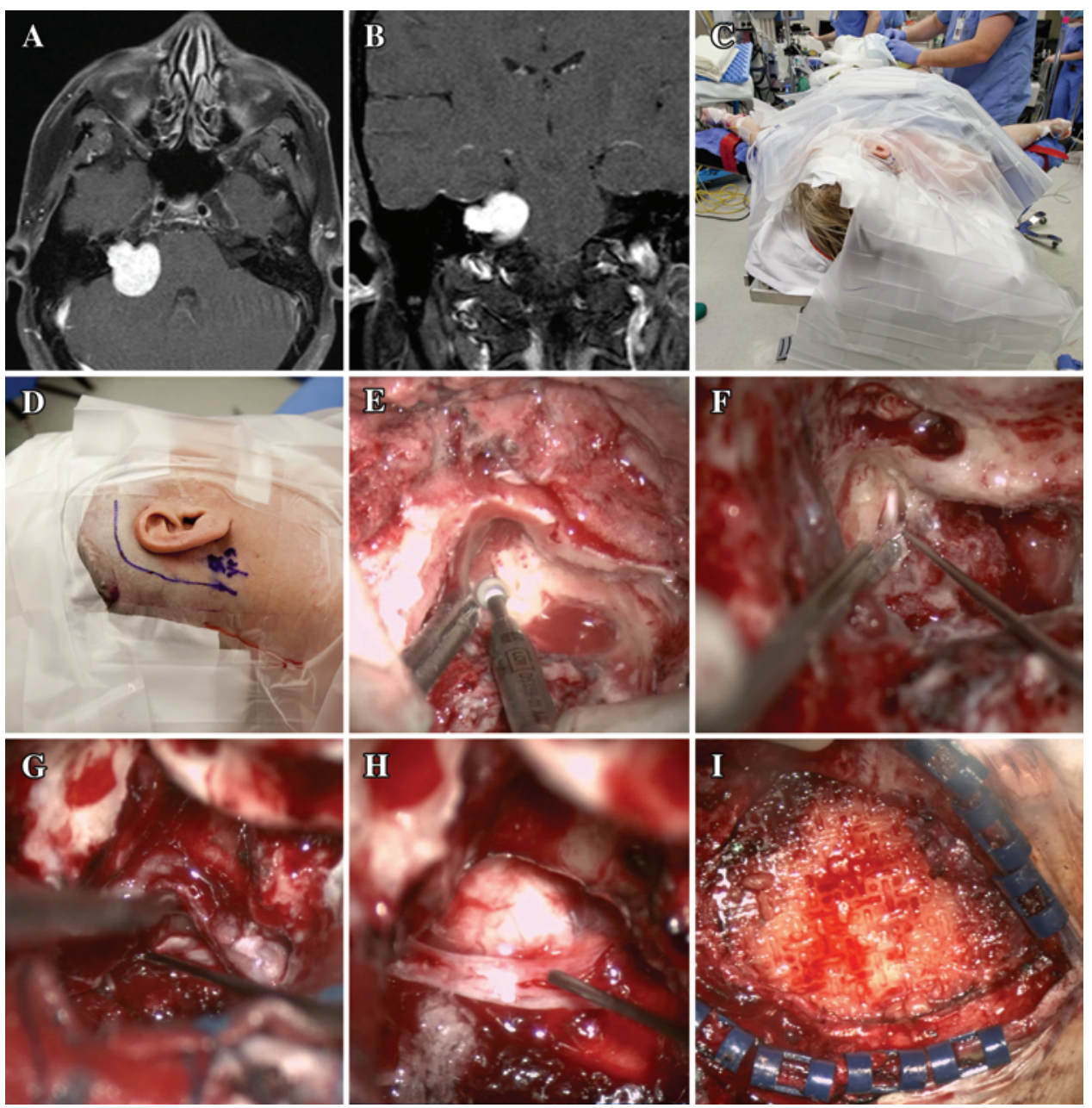

FIG. 1. Axial (A) and coronal (B) T1-weighted MRI studies obtained with contrast enhancement of the brain showing a VS occupying the right CPA and extending into the IAC of a 42-year-old woman who presented with a history of hearing loss in the right ear. C-I: Intraoperative photographs obtained during the translabyrinthine approach to the tumor. C: The patient is positioned supine, and her head is rotated to the contralateral side. D: A hockey stick-shaped retroauricular skin incision extending behind the mastoid tip is made. E: The mastoidectomy is performed with the high-speed drill. F: After the dura of the IAC is opened, the facial nerve is located and confirmed using stimulation. The vestibular nerves are cut, and the tumor is dissected from the facial nerve. G: The tumor is debulked with extracapsular dissection. The root entry zone of the facial nerve at the brainstem is identified and confirmed with stimulation, and then the tumor is gently reflected laterally and dissected from the facial nerve under direct visualization. H: After tumor removal, the facial nerve is stimulated at the root entry zone. I: Free abdominal fat is used to close the dural defect and occlude the mastoidectomy cavity. The bone defect is covered with a mesh implant.

laterally and superiorly to dissect it away from the facial nerve under direct vision.

After tumor removal and hemostasis, free abdominal fat is used to close the dural defect and occlude the mastoidectomy cavity. The bone defect is covered with a mesh implant. The rest of the closure is done using 2-0 Vicryl interrupted sutures for the galea and 4-0 Vicryl in a subcuticular fashion for the skin. This offers the advantage that the stitches do not have to be removed.

\section{The Retrosigmoid Approach}

The retrosigmoid approach (Fig. 2, Video 2) provides a trajectory that is parallel to the petrous bone.

VIDEO 2. Clip showing the right retrosigmoid approach for resection of a VS. Click here to view with Media Player. Click here to view with Quicktime.
It allows removal of tumors of different sizes and offers the possibility of hearing preservation. ${ }^{5,7}$ The senior authors prefer this approach for tumors with significant mass in the cistern and in patients with serviceable hearing, in whom hearing preservation is the goal. The advantage is that the approach offers the surgeon a wide view of the cisternal component of the tumor and thus good access to the root entry zone of the acoustic nerve. The disadvantages include the necessity for cerebellar retraction and less access to the facial and cochlear nerves in the distal IAC, which increases the potential to leave a residual tumor fragment behind.

Patients with tumors that do not involve the lateral one-third of the IAC and do not impinge on the brainstem are the best candidates for hearing preservation. For a medium-to-large tumor $(>2.5-3 \mathrm{~cm})$ that extends far lateral to the fundus of the IAC in a patient with good hearing, 

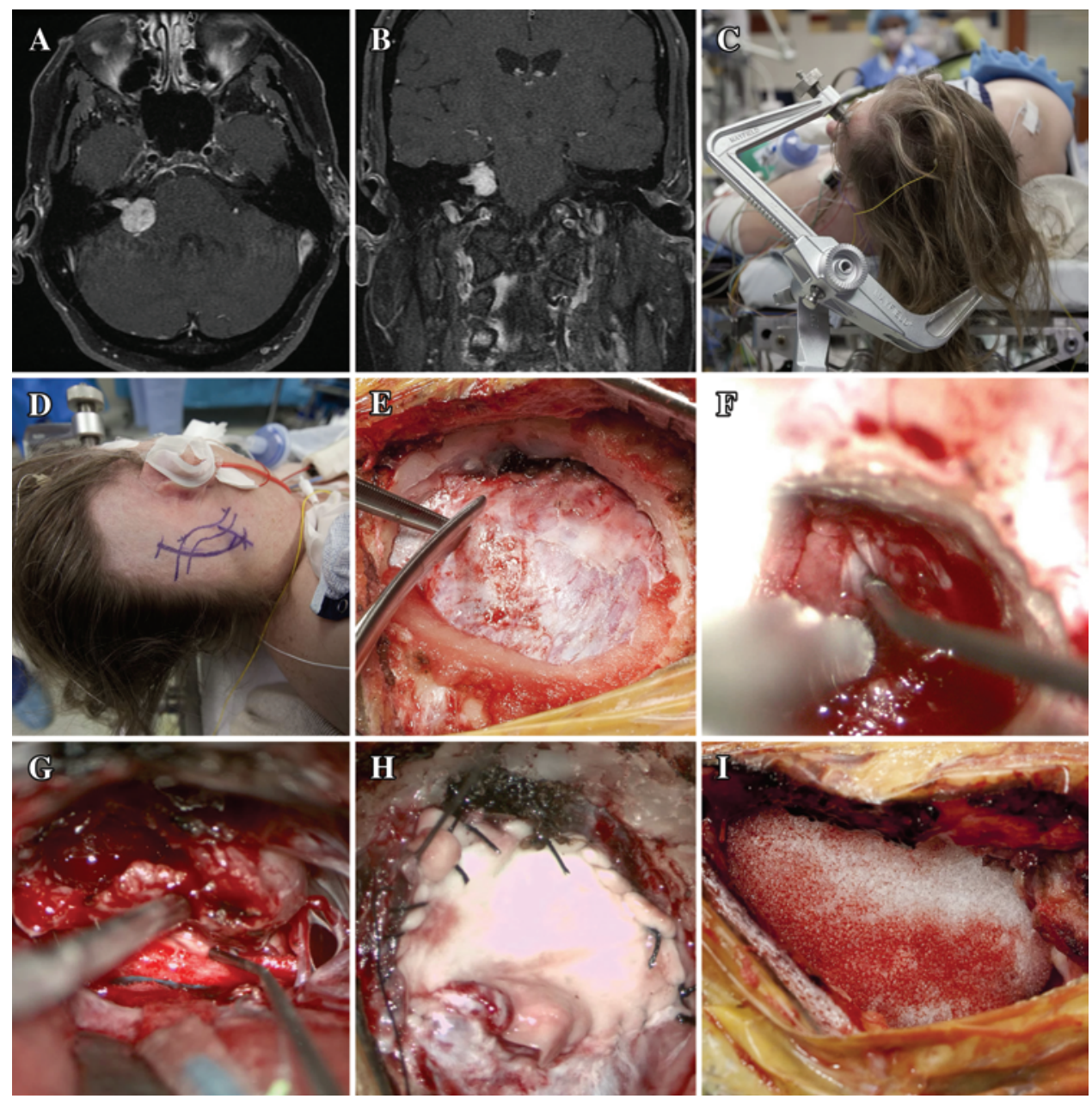

FiG. 2. Axial (A) and coronal (B) T1-weighted MRI studies with contrast enhancement showing a VS occupying the right CPA and extending into the IAC of a 59-year-old woman. She presented with a history of tinnitus and decreased hearing in the right ear, and her audiogram showed that she had serviceable hearing on the right side. C-I: Intraoperative photographs obtained during the retrosigmoid approach to the tumor. C: The patient is placed supine or in the lateral position, and the head is fixed in a Mayfield 3-point head holder. D: The incision is located approximately 2 fingerbreadths behind the pinna of the ear. The planned suboccipital craniectomy exposes the edges of the transverse and sigmoid sinuses. E: The dura is opened parallel to the sinuses and then retracted with 4-0 silk sutures. F: The posterior lip of the IAC is drilled, the vestibular nerves are divided, and the facial nerve is identified anterior to them and confirmed with stimulation. The cochlear nerve is identified just inferolateral to the facial nerve. G: The tumor is then dissected off the cerebellum and brainstem and debulked using the ultrasonic aspirator. The root entry zones of the facial and cochlear nerves at the brainstem are identified, and the facial nerve is confirmed with stimulation. The tumor is dissected off these 2 nerves very carefully and under direct vision. H: After tumor removal, the dura is closed in a watertight fashion by using an AlloDerm patch. I: The bone defect is covered with Medpor cranioplasty (porous polyethylene implant).

we believe that hearing preservation is not likely and that the retrosigmoid approach does not adequately expose the lateral end of the IAC. We believe that such cases are best managed via the translabyrinthine approach.

The patient is placed in the lateral position, and the head is fixed in a Mayfield 3-point head holder. Somatosensory evoked potentials, motor evoked potentials, and facial nerve monitoring are used. Brainstem auditory evoked responses are also used when hearing preservation is attempted.

The incision is located approximately 2 fingerbreadths behind the pinna of the ear. A suboccipital craniectomy is performed, and the edges of the transverse and sigmoid sinuses are exposed. The air cells are care- fully waxed to prevent CSF leakage. The dura mater is then opened in a cruciate fashion such that there is a flap superiorly and laterally to allow flat trajectory along the axis of the sigmoid sinus, and the cerebellum is gently retracted to expose the tumor in the CPA. The posterior lip of the IAC is drilled until the transverse crest can be palpated with a hook. The drilling is performed using a diamond drill bit and with copious irrigation to prevent thermal injury. The retrosigmoid approach exposes $180^{\circ}$ of the circumference of the IAC. During drilling, extensive irrigation is used to avoid any thermal damage to the nerves in the canal. Air cells at this level can be opened during the drilling and should also be waxed to prevent CSF leakage. 
Nuance for Nerve Dissection

The vestibular nerves are divided, and the facial nerve is identified anterior to them and confirmed with stimulation. The cochlear nerve is identified just inferolateral to the facial nerve. Specific techniques for preserving the facial and vestibular nerves when dissecting from the tumor include gentle dissection using fine otology instruments, such as the right-angled hook used in the video. The tumor is dissected from medial to lateral to avoid traction on the cochlear nerve as it exits the perforated bone at the end of the IAC. Careful dissection is performed under direct visualization, and the interface of the nerve with the tumor is dissected under high magnification. Both facial nerve and brainstem auditory evoked response monitoring are used during this dissection.

The senior authors use automated irrigation systems during the removal of VSs to avoid desiccation of the nerves. The labyrinthine artery is carefully preserved, and up to $1 \mathrm{ml}$ of papaverine diluted in $10 \mathrm{ml}$ of saline at room temperature administered locally is used to treat vasospasm. The rationale for using diluted solution is to avoid any potential for cranial nerve injury. The tumor is then dissected off the cerebellum and brainstem and is debulked using the ultrasonic aspirator, which makes the extracapsular dissection proceed more easily. The root entry zones of the facial and acoustic nerves at the brainstem are identified, and the facial nerve is confirmed with stimulation. The tumor is dissected off these 2 nerves very carefully and under direct vision. Once the tumor is removed and hemostasis is obtained, the dura is closed in a watertight fashion by using an AlloDerm patch (if necessary). The bone defect is covered with Medpor cranioplasty (porous polyethylene implant). The muscular layer and the galea are then closed using 2-0 Vicryl interrupted sutures. The skin is closed in a subcuticular fashion by using 4-0 Vicryl.

\section{The Middle Fossa Approach}

The middle fossa approach (Fig. 3, Video 3) exposes the IAC and its contents from a superior trajectory.

VIDEo 3. Clip showing the middle fossa approach for resection of a VS. Click here to view with Media Player. Click here to view with Quicktime.

It is chosen for small tumors located primarily within the IAC and offers the possibility of hearing preservation. ${ }^{6,7}$ It is an excellent approach for small tumors that predominately occupy the IAC with a minor component in the cistern (usually $<10 \mathrm{~mm}$ ); it provides exceptional access to the lateral end of the canal.
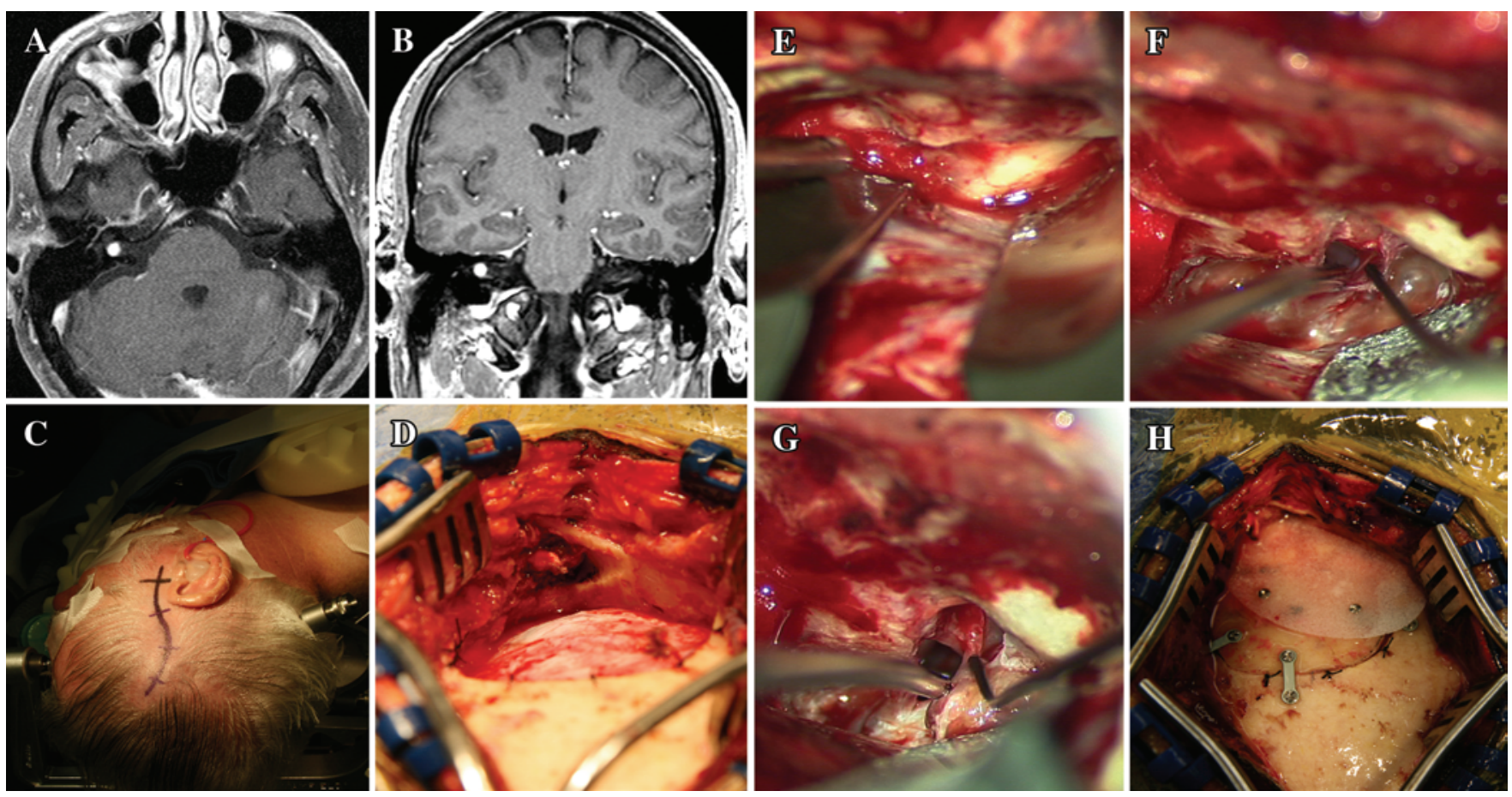

FIG. 3. Axial (A) and coronal (B) T1-weighted MRI studies of the brain showing a VS occupying the distal aspect of the right IAC of a 60 -year-old man who presented with a history of dizziness. C-H: Intraoperative photographs obtained during a middle fossa approach to the tumor. C: The head of the patient is fixed in the Mayfield 3-point head holder and positioned parallel to the floor. A lazy S-shaped skin incision is made anterior to the tragus; it extends from the zygomatic arch inferiorly to the temporal line superiorly. D: The craniotomy is positioned with one-third posterior and two-thirds anterior to the external auditory canal. The craniotomy has to be as low as possible, flush with the cranial base, and additional drilling is performed if the craniotomy flap is not low enough. E: The dura is then elevated from posterior to anterior, the edge of the petrous ridge is exposed, and then drilling is performed to expose the IAC. F: The dura of the IAC is opened. G: The vestibular nerves are divided; the facial nerve is identified anterior to them and confirmed with stimulation. The cochlear nerve is identified inferior to the facial nerve. The tumor is then dissected off the facial and cochlear nerves while preserving all the blood vessels. $\quad \mathrm{H}$ : The craniotomy flap is then replaced. A Medpor cranioplasty is used to cover the bone defect in case of additional drilling during the opening. 
The patient's head is fixed in the Mayfield 3-point head holder and positioned parallel to the floor. Facial nerve monitoring and brainstem auditory evoked responses are used. A lazy S-shaped skin incision is made anterior to the tragus; it extends from the zygomatic arch inferiorly to the temporal line superiorly. The temporalis muscle and fascia are cut vertically and retracted with a self-retaining retractor. The craniotomy is positioned with one-third posterior and two-thirds anterior to the external auditory canal. The craniotomy has to be as low as possible, flush with the cranial base; additional drilling is performed if the craniotomy flap is not low enough. The dura is then elevated from posterior to anterior to prevent injury to the greater superficial petrosal nerve.

After the edge of the petrous ridge is exposed, drilling is performed to identify the superior semicircular canal; this is followed anteriorly to the geniculate ganglion, and then drilling is continued medially to expose the IAC. The basal turn of the cochlea lies very close to the labyrinthine segment of the facial nerve. When dissecting the lateral end of the IAC, it is imperative to be aware of this relationship and keep that dissection very tight to the facial nerve course in the labyrinthine segment. Typically, it is possible to dissect this area with a $2-\mathrm{mm}$ diamond bur, which allows for adequate exposure of the facial nerve but without violating the cochlea.

Once the roof of the IAC is drilled, the dura of the IAC is opened along its posterior aspect along the axis of the IAC, away from the course of the facial nerve. The vestibular nerves are divided; the facial nerve is identified anterior to them and confirmed with stimulation. The cochlear nerve is identified inferior to the facial nerve. The tumor is then dissected off the facial and cochlear nerves while preserving all the blood vessels. The tumor may be located ventral to the facial nerve. In this case, the facial nerve is carefully dissected from the superior aspect of the tumor.

After tumor removal and hemostasis, fat graft is placed into the IAC to prevent CSF leakage. The craniotomy flap is then replaced. A Medpor cranioplasty is used to cover the bone defect if additional drilling is needed during the opening. The rest of the closure is done layer by layer, with closure of the muscle, fascia, galea, and skin. The temporalis muscle and fascia are closed using interrupted 2-0 Vicryl sutures; the galea is closed with 3-0 Vicryl, and the skin is closed in a subcuticular fashion by using 4-0 Vicryl.

\section{Conclusions}

The contemporary surgical management of VS is facilitated by familiarity with all 3 approaches described above. Indications for approaches depend on the size of the tumor, its location, the quality of preoperative hearing, and the desire for attempts at hearing preservation. Meticulous microsurgical technique for dissection of the tumor from the adjacent facial and cochlear nerves, electrophysiological adjuncts such as intraoperative cranial nerve monitoring, and careful closure to prevent CSF leakage are critical technical aspects of these surgical approaches.

\section{Disclosure}

Dr. Shelton received support from the Cochlear Corporation for a non-study-related clinical or research effort that he oversaw. The authors report no conflict of interest concerning the materials or methods used in this study or the findings specified in this paper.

Author contributions to the study and manuscript preparation include the following. Conception and design: Couldwell. Acquisition of data: Couldwell. Drafting the article: Chamoun. Critically revising the article: Couldwell, MacDonald, Shelton. Reviewed submitted version of manuscript: all authors. Approved the final version of the manuscript on behalf of all authors: Couldwell.

\section{References}

1. Angeli S: Middle fossa approach: indications, technique, and results. Otolaryngol Clin North Am 45:417-438, ix, 2012

2. Arriaga MA, Lin J: Translabyrinthine approach: indications, techniques, and results. Otolaryngol Clin North Am 45:399415, ix, 2012

3. Arthurs BJ, Fairbanks RK, Demakas JJ, Lamoreaux WT, Giddings NA, Mackay AR, et al: A review of treatment modalities for vestibular schwannoma. Neurosurg Rev 34:265-279, 2011

4. Elhammady MS, Telischi FF, Morcos JJ: Retrosigmoid approach: indications, techniques, and results. Otolaryngol Clin North Am 45:375-397, ix, 2012

5. Gharabaghi A, Samii A, Koerbel A, Rosahl SK, Tatagiba M, Samii M: Preservation of function in vestibular schwannoma surgery. Neurosurgery 60 (2 Suppl 1):ONS124-ONS128, 2007

6. Kutz JW Jr, Scoresby T, Isaacson B, Mickey BE, Madden CJ, Barnett SL, et al: Hearing preservation using the middle fossa approach for the treatment of vestibular schwannoma. Neurosurgery 70:334-341, 2012

7. Rabelo de Freitas M, Russo A, Sequino G, Piccirillo E, Sanna M: Analysis of hearing preservation and facial nerve function for patients undergoing vestibular schwannoma surgery: the middle cranial fossa approach versus the retrosigmoid approach-personal experience and literature review. Audiol Neurootol 17:71-81, 2012

Manuscript submitted May 15, 2012.

Accepted June 15, 2012.

Please include this information when citing this paper: DOI: 10.3171/2012.6.FOCUS12190.

Supplemental online information:

Video 1: http://mfile.akamai.com/21490/wmv/digitalwbc.download. akamai.com/21492/wm.digitalsource-na-regional/FOCUS12-190_ video_1a.asx (Media Player).

http://mfile.akamai.com/21488/mov/digitalwbc.download.akamai. com/21492/qt.digitalsource-global/FOCUS12-190_video_1a.mov (Quicktime).

Video 2: http://mfile.akamai.com/21490/wmv/digitalwbc.download. akamai.com/21492/wm.digitalsource-na-regional/FOCUS12-190_ video_2a.asx (Media Player).

http://mfile.akamai.com/21488/mov/digitalwbc.download.akamai. com/21492/qt.digitalsource-global/FOCUS12-190_video_2a.mov (Quicktime).

Video 3: http://mfile.akamai.com/21490/wmv/digitalwbc.download. akamai.com/21492/wm.digitalsource-na-regional/FOCUS12-190_ video_3a.asx (Media Player).

http://mfile.akamai.com/21488/mov/digitalwbc.download.akamai. com/21492/qt.digitalsource-global/FOCUS12-190_video_3a.mov (Quicktime).

Address correspondence to: William T. Couldwell, M.D., Ph.D., Department of Neurosurgery, Clinical Neurosciences Center, University of Utah, 175 North Medical Drive East, Salt Lake City, Utah 84132.email: neuropub@hsc.utah.edu. 